\title{
SEISMIC AND GRAVITY INVESTIGATIONS ON THE MALASPINA GLACIER, ALASKA
}

\author{
Clarence R. Allen and George I. Smith \\ (Contribution No. 617, Division of the Geological Sciences, \\ California Institute of Technology, Pasadena, California)
}

\begin{abstract}
Seismic reflections obtained from bedrock beneath the Malaspina Glacier along a ten-mile profile line indicate ice thicknesses ranging from 1130 to $2050 \mathrm{ft}$. The base of the ice is $700 \mathrm{ft}$ below sea level near the center of the profile and shallows both northward toward the mountains and southward toward the ice margin. Good reflections were obtained with dynamite charges of about one ounce in $26-\mathrm{ft}$ water-filled shot holes but only in relatively crevasse-free areas. Deeper reflections substantiate the inferred sedimentary nature of the subglacial rocks and show geologic structures consistent with the regional pattern. Gravity measurements along the central three miles of the seismic profile line indicate a gentle northwest-southeast trending subglacial topographic grain. Seismic refraction shots beyond the present margin of the glacier suggest a thickness of unconsolidated proglacial deposits in excess of $500 \mathrm{ft}$.
\end{abstract}

\section{Introduction}

During July and August, 1951, seismic and gravity investigations were carried out on the Malaspina Glacier of southeastern Alaska (Fig. 1) for the purpose of determining ice thickness and configuration of the subglacial floor. Although of interest in itself, the geophysical informaton was obtained primarily to aid in the investigation of structural relationships and modes of low within this glacier. The Malaspina, a fan-shaped sheet of ice covering more than $1000 \mathrm{sq}$ $\mathrm{mi}$, is the type example of a piedmont glacier as defined by [RUSSELL [1891]. Its present regime is one of rapid deterioration [SHARP, 1951]. Twenty-seven days were devoted to seismic studies and ten days to gravity measurements.

\section{Seismic reflection shooting}

General statement--Seismic reflections were obtained along a ten-mile north-south profile line passing through Glacier Campandaligned approximately parallel to the assumed direction of ice flow inferred from structures in the ice (Fig. 1). The usual interval between shooting stations along this line was $5000 \mathrm{ft}$. The nature of the ice-bedrock interface beneath the glacier can only be surmised, but the regional geology [RUSSELL, 1892; TARR and BUTLER, 1909; MILLER, 1951] suggests that early Tertiary clastic sedimentary rocks of the Yakataga and Poul Creek formations lie beneath the ice. Reflections from several deep horizons tend to substantiate the sedimentary nature of the subglacial rocks. The reflection coefficient of an interface between ice and sedimentary rock might conceivably be small (high velocity, low density versus high density, low velocity), but in this area a good reflection coefficient in the order of 0.4 is suggested by the high degree of consolidation of the Yakataga series where exposed 30 miles to the west.

Seismic procedure--A century six-trace portable seismic outfit was used. It was mounted on a toboggan sled which could be hauled by two men over smooth ice, but three men were required in moderately crevassed areas. Moving the seismic equipment from station to station usually required more time than the actual setting-up and shooting operation. Use was made of the project's helicopter on several occasions, but poor weather and limited gasoline restricted its operation more than anticipated.

The following conditions were required for the recording of recognizable reflections:

(1) Crustal conditions--Except in the earliest phases of the operation, snow from the previous winter was absent from the glacier's surface, so for the most part geophones were placed sirectly on glacier ice and all shot holes bottomed in ice, not in snow or firn. The best records Tere obtained from areas in which the ice was relatively thin, with all the openings seemingly filled with water, and the surface smooth. Poor results were obtained in crevassed areas in which the ice was riven with fractures and lacking water even in deep openings. The foliation and sizes of crystals seemed to have no effect. Along the seismic profile line, the ice was essentially free of debris except for local accumulations of surficial silt. 


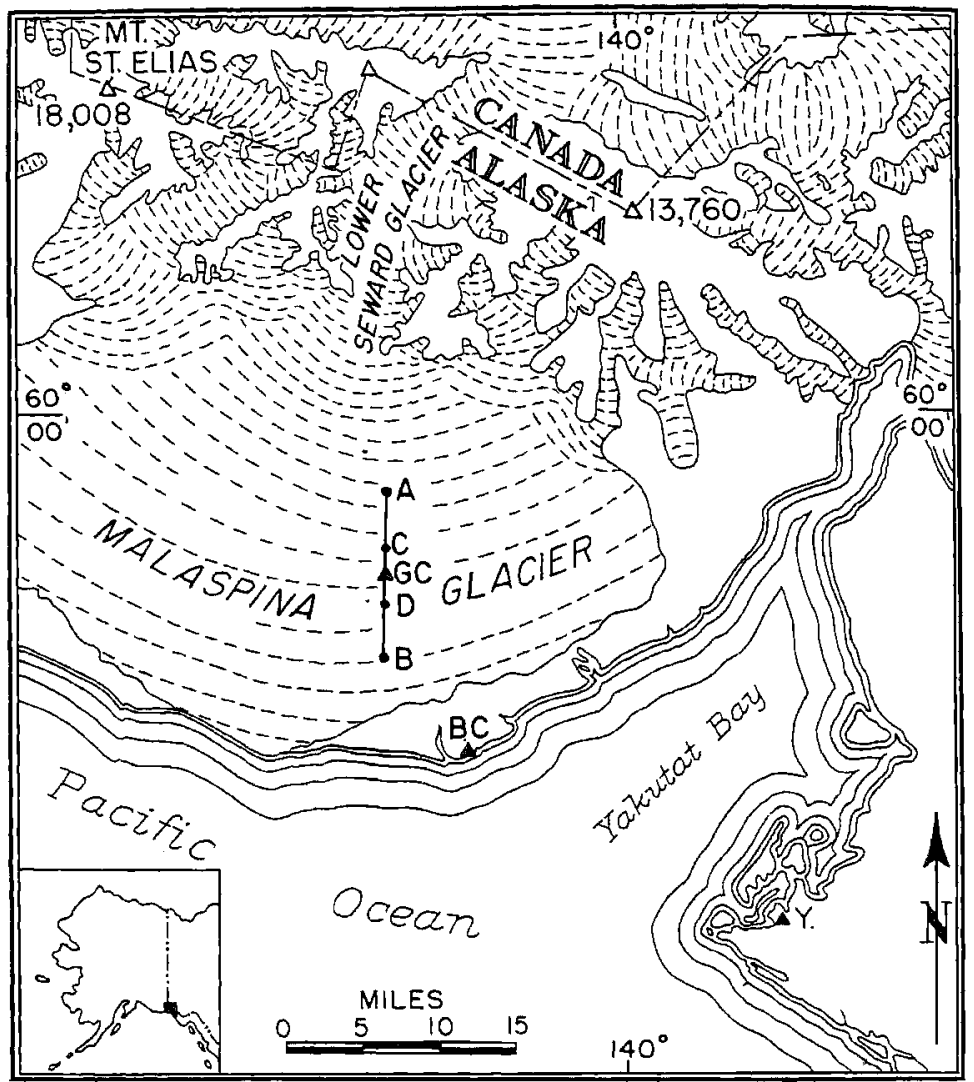

Fig. 1--Map of Malaspina Glacier and vicinity; $Y$, Yakutat Village; BC, Beach Camp; GC, Glacier Camp; A-B, seismic profile line; C-D, gravimeter profile line

(2) Size and placement of the explosive charge--The procedure finally developed was to place a charge of about one ounce of 60 pct high-velocity gelatin, tamped with water, in a $11 / 2$ inch hole drilled to a depth of $26 \mathrm{ft}$.

As a result of the interest expressed by many persons in the problems of mechanical drilling in glacier ice, a drawing of the ice drill used in making shot holes is included (Fig. 2). This drill, modified from AHLMANN [1935] after Koch and Wegener, was the most satisfactory of several experimental models. Drilling was in coarsely crystalline ice, not firn. If the drill point was correctly sharpened, about 100 turns were needed to fill the drill barrel, and approximately 30 fillings were needed to make a 26 -ft hole (the total length of the drill plus seven extensions). The time necessary for each drill hole was approximately two hours. This includes the drilling time as well as that required to remove and empty the drill barrel every load.

No satisfactory reflections were obtained from charges less than $20 \mathrm{ft}$ deep in spite of numerous attempts. Experimentation was simple because the holes did not deteriorate with repeated shooting. The following techniques were also unsuccessful: charges in crevasses or water-filled moulins even though at considerable depth, charges without water tamping, use of a cap alone, dropping a sledge or hammering on the surface, or shooting single charges of various sizes in the air. No geometric patterns of air charges were set off, as recommended by POULTER [1950], chiefly because of a lack of suitable detonating equipment.

For convenience in setting-up, a $\mathrm{T}$ spread was used, with an offset of 10 to $20 \mathrm{ft}$ and a geophone spacing of 50 or $100 \mathrm{ft}$. Orientation of the geophone spread relative to the trend of crevasses seemed to have little effect on the recorded amplitudes of surface waves. Consequently the geophones were usually aligned east-west (perpendicular to the profile line) simply because this was the orientation of the smooth and easily-traversed ice "bands." 


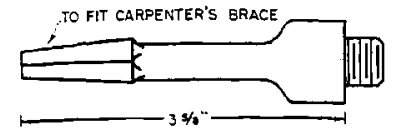

BFACE ADAPTER (STEEL)
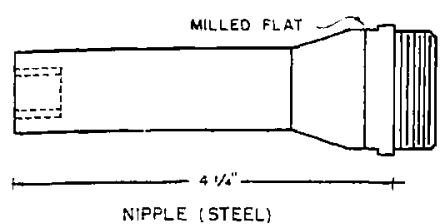

NIPPLE (STEEL)

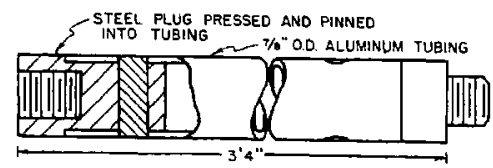

EXTENSION

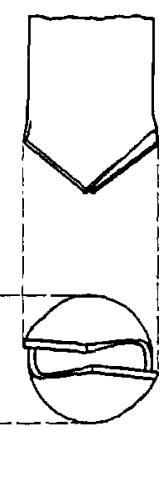

DRILL

(3) Electronic settings--Amplifier gains had to be kept low because of continual wind and the noise of water running in crevasses. No automatic volume control, expander, or mixing was used. Fitters were set at 25-80 cps, the widest possible band-pass. Four. of the amplifiers $(1,2,4$, and 6 in Fig. 3) were modified in the field for higher frequency response up to about $125 \mathrm{cps}$.

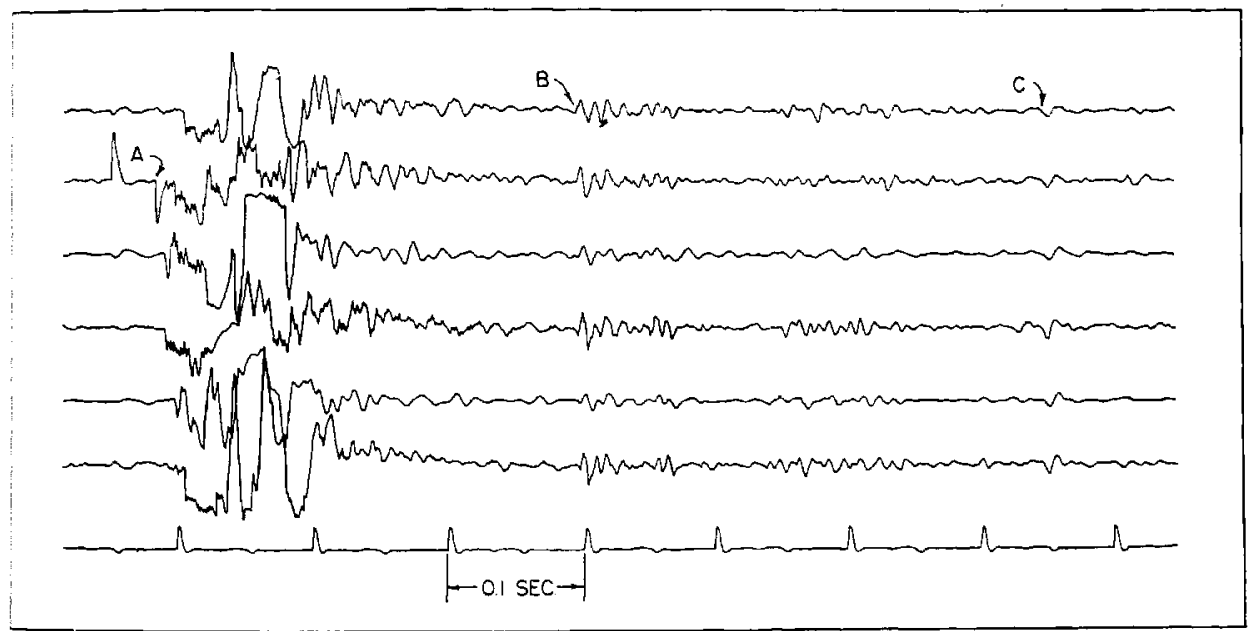

Fig. 3--Copy of seismic record 90 from station 15-S; "T" spread, 20-ft offset, 100-ft geophone interval, 2/3-oz charge at 26-ft depth; A, time break (earlier pip is cap make); B, bedrock reflection, 1930-ft depth; $\mathrm{C}$, deeper sedimentary horizon reflection, $3700-\mathrm{ft}$ depth

Interpretation of the seismic records--Refraction shots at Glacier Camp indicate a compressional wave velocity in this ice of $12,320 \mathrm{ft} / \mathrm{sec}$, with a probable error of $30 \mathrm{ft} / \mathrm{sec}$. Shotpoint to geophone distances ranged from 25 to $2133 \mathrm{ft}$, and the time-distance curve gives no evidence of increasing velocity with depth.

The constant velocity - with-depth relationship permits a simple arithmetic calculation of ice thickness based on shot depth, reflection time, and seismic velocity. Data for the various stations and the cha:iges in ice thickness aiong the seismic profile are illustrated in Figure 4. It is noteworthy that the subglacial floor is below sea level along the entire seismic profile, reaching depths of more than $700 \mathrm{ft}$ below sea level in the central part of the profile line. The ice becomes thinner both northward toward the mountains and southward toward the ice margin. No "step-out" was observed on any of the reflections from the ice-bedrock interface, suggesting a relatively smooth subglacial topography. Nothing was found corresponding to the horizontal velocity zones reported by GOLDTHWAIT [1936] in the Crillon Glacier. 


SOUTH

Fig. 4--Seismic profile across Malaspina Glacier; size of dot represents relative strength of reflection

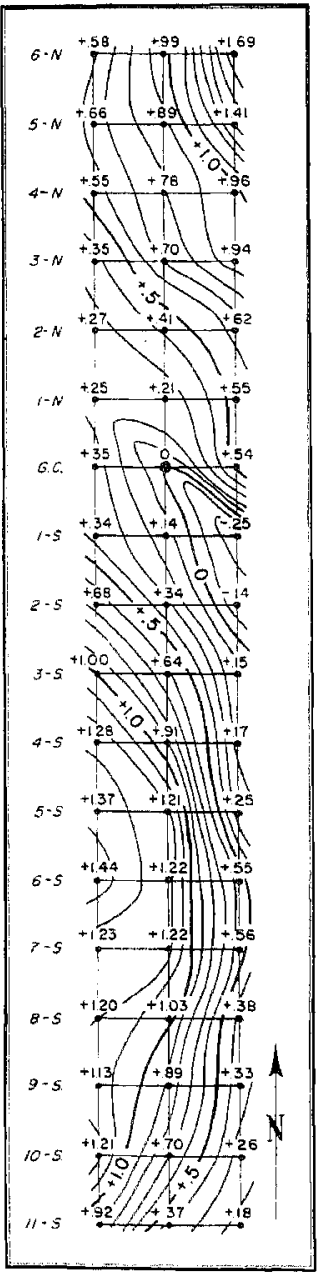

Fig. 5--Gravity map; values in milligals, stations $1000 \mathrm{ft}$ apart
Many of the records show reflections from horizons within the sedimentary section beneath the glacier. Neither amplitudes nor arm rival times of these pulses are suitable for multiples. Depths plotted in Figure 4 have been computed by using $10,000 \mathrm{ft} / \mathrm{sec}$ as a plausible seismic velocity for the rocks exposed in the Yakataga area, which are assumed to extend eastward beneath the Malaspina Glacier. Anay. sis of all the deep reflections, some of which show a significant "step-out," suggests a north-dipping homoclinal structure, and this would be compatible with the regional structure mapped in the Yakataga district.

\section{Gravity investigations}

General statement--In order to test the suitability of gravimeter measurements for determining more detail in the subglacial topograps: a network of gravity stations was set up from station $6-\mathrm{N}$ to $11-\mathrm{S}$ of the seismic profile (Fig. 4). This three-mile interval was chosen because seismic work had indicated a 300 -ft ridge beneath station $5-S$, and a gravity survey offered hope of better delineation of this feature. Theoretically, gravity measurements should produce definitive results because of the high density contrast between ice and rock.

Gravity procedure--A 54-station gravity network with a 1000 -ft grid was set up as illustrated in Figure 5. The relative elevations of stations were measured with a microaltimeter loaned by the United Geophysical Co. This instrument had the advantage of speed and convenience over transit surveying, although peculiar meteorological conditions on the glacier necessitated lengthy computations and probably limited the accuracy to plus or minus one foot. An Atlas Exploration Co. Model F gravimeter was used, and the ruggedness and lightness of this instrument proved convenient. Leveling the gravimeter was a serious problem owing to differential pressure-melting beneath the supports, but this difficulty was partly alleviated by setting the tri" pod on a wooden board which had first been placed firmly on the ice surface. Drift correction data were obtained in the field by means of a looping-back pattern. Corrections for elevation and latitude were made in the normal manner, and the smooth surface of the ice and the distance of the mountains obviated the necessity of any terrain correction.

Gravity map--The corrected gravity readings are plotted and contoured in Figure 5. From this map, several conclusions may be drawn:

(1) The local trend of subglacial topographical features is appar" ently northwest-southeast. This is in contrast to the east-west orierjation of structures within the ice along the profile line.

(2) Owing to this trend, a "two-dimensional mass" interpretation. [HUBBERT, 1948] based upon a single north-south gravity traverse would give misleading results.

(3) Inasmuch as the gravity anomalies are relatively small, there is no reason to expect major relief on the glacier floor. 
Configuration of the bedrock floor--Gravity at depth has been calculated by well-known methods described by EVJEN [1936] and BULLARD and COOPER [1948]. The second vertical derivative at each station along the center line may be approximated by using second differences and applying Laplace's equation. First vertical derivatives are calculated by assuming that each gravity reading is constant in a 1000 -ft square surrounding that station and then integrating, applying the inverse-square law, in order to compute gravity $300 \mathrm{ft}$ in the air over each center-line station. (With only three rows of stations, this height must be small relative to the distance between stations.) The first vertical derivatives may now be approximated by first jifferences, and it can be shown that the first derivative below the surface differs by only a constant from this value calculated for above the surface. With these computed values of the first and second derivatives, gravity may now be extended downward to any sufficiently small depth by a Maclaurin series, and the relief of a discontinuity at this depth, assuming a given density contrast, may be calculated as outlined by EV JEN [1936]. Figure 6 shows the detailed

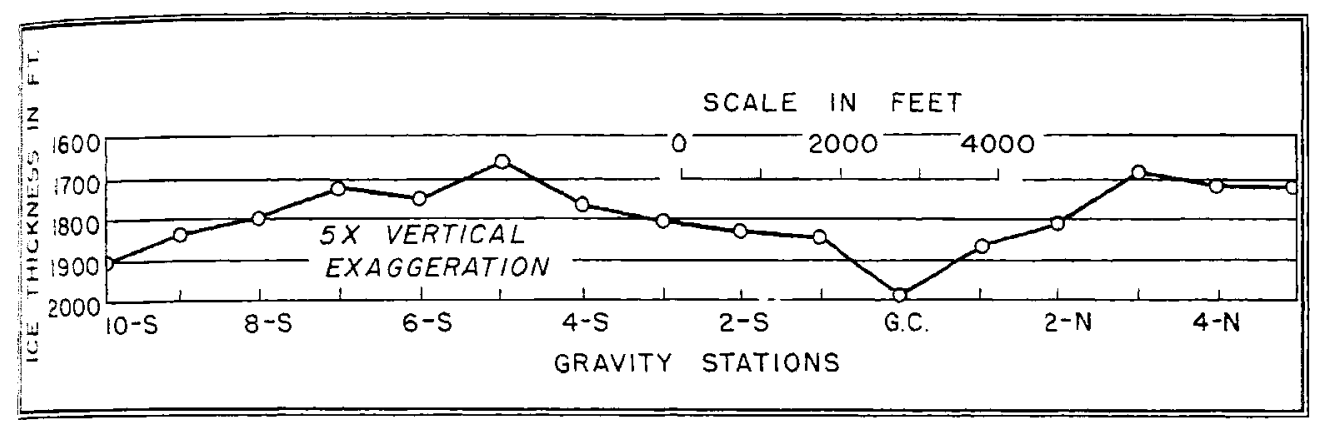

Fig. 6--Ice thickness between stations $10-\mathrm{S}$ and 5-N on basis of gravity measurements

topography of the bedrock floor along the gravity profile, using seismic depths at Glacier Camp and station $10-\mathrm{S}$ as the basis for depth extension and regional gradient correction. The results substantiate the relative smoothness of the glacier floor and verify the existence of a $300-\mathrm{ft}$ ridge beneath station 5-S. Furthermore, this ridge is probably of bedrock and not due to locai accumulation of subglacial drift. The discrepancy between the seismic and gravity depths at station $5-\mathrm{N}$ is probably due to failure to pick the true bedrock reflection on the extremely poor seismic records from this station.

\section{Comparison of seismic and gravity operations}

The low relief of the glacier surface, together with the high density contrast between ice and rock, suggests that gravity measurements might be the best means of quickly determining ice thickness. The Malaspina operation, however, points up several drawbacks. Interpretation of gravity data requires that the ice thickness be known in at least one location, unless jperations are close to the ice margin [LITTLEWOOD, 1952]. In most instances, this information could best be supplied by seismic techniques, and once seismic equipment has been moved onto the glacier, its continued use might be more efficient than switching to gravity exploration. Leveling the gravimeter on ice constitutes a serious problem, as does the accurate surveying and marking of stations. Lack of time and suitable office facilities, moreover, precludes full analysis of gravity data until long after field operations are concluded. Seismic calculations, on the other hand, are simple enough so that the effectiveness of the operation can be determined as it progresses. This argument takes on added importance in view of the isolated nature of glacier field studies. Seismic reflection shooting seems to be well suited for determination of glacier thicknesses, especially where the crevassing is not severe and the firn layer is thin or absent.

\section{Seismic refraction shooting on proglacial deposits}

Near the Beach Camp (Fig. 1) two refraction profiles were shot on the proglacial deposits with the hope of determining their thickness. Presumably, the bulk of this unconsolidated material outside the present margin of the Malaspina is glacial drift. At a maximum shot-point to seophone distance of $4500 \mathrm{ft}$, a break in the time-distance curve had not yet been reached. The measured shallow velocity was $6400 \mathrm{ft} / \mathrm{sec}$, but conclusions as to the thickness of this layer depend upon an assumed velocity in the underlying bedrock. Minimum bedrock velocity inferred from the regional geology suggests a thickness of drift of not less than $500 \mathrm{ft}$. If bedrock is truly $500 \mathrm{ft}$ or more below sea level at Beach Camp, the seismically-determined $-150-\mathrm{ft}$ level of 
bedrock at station $30-\mathrm{S}$ of the glacier profile indicates a considerable bedrock lip near the present snout of the glacier. An alternative interpretation, perhaps geologically more reasonable, is that the shallowest reflection at station $30-\mathrm{S}$ is not from bedrock but from the interface between ice and unconsolidated drift that lies beneath the glacier near its margin. Such a contact would have a very poor reflection coefficient, and the much stronger reflection from $-800 \mathrm{ft}$ at this location may well represent the actual bedrock surface beneath the drift.

\section{Acknowledgments}

The field work was done under the supervision of R. P. Sharp and the office work under C. H. Dix; both have criticized the manuscript and their guidance is gratefully acknowledged. D. L. Baker and G. P. Rigsby took considerable time from their own field projects to aid in the geophysical work. Valuable equipment was loaned by the United Geophysical Co, and the Atlas Exploration Co. The work was done under the sponsorship of the Office of Naval Research (Coatract N6onr-244-16), the Arctic Institute of North America, and the California Institute of Technology.

\section{References}

AHLMANN, H. W., Scientific results of the Norwegian-Swedish Spitzbergen Expedition in 1934; Part I, The stratification of the snow and firn on Isachsen's Plateau, Geogr. An., v. 17, pp. $29-42,1935$.

BULLARD, E. C., and R. I. B. COOPER, The determination of the masses necessary to produce a given gravitational field, Proc. R. Soc. London, ser. A, v. 194, pp. 332-347, 1948.

EVJEN, H. M., The place of the vertical gradient in gravitational interpretations, Geophysics, v. 1 , pp. $127-136,1936$.

GOLDTHWAIT, R. P., Seismic sounding on South Crillon and Klooch Glaciers, Geogr. J., v. 87, w. $496-517,1936$.

HUBBERT, M. K., A line-integral method of computing the gravimetric effects of two-dimensional masses, Geophysics, v. 13, pp. 215-225, 1948.

LITTLEWOOD, C. A., Gravity measurements on the Barnes Icecap, Baffin Island, Arctic, v. 5, pp. 118-124, 1952 .

MILLER, D. J., Preliminary report on the geology and oil possibilities of the Yakataga district, Alaska, U. S. Geol. Surv. mimeographed report, April, 1951.

POULTER, T. C., The Poulter seismic method of geophysical exploration, Geophysics, v. 15, po. 181-207, 1950.

RUSSELL, I. C., An expedition to Mount St. Elias, Alaska, Nat. Geogr. Mag., v. 3, pp. 53-204, 1881.

RUSSELL, I. C., Second expedition to Mount St. Elias, in 1891, Thirteenth An. Rep. U. S. Geol. Surv., pt. 2, pp. 1-92, 1892.

SHARP, R.P., Accumulation and ablation on the Seward-Malaspina Glacier system, CanadaAlaska, Geol. Soc. America Bull., v. 62, pp. 725-744, 1951.

TARR, R. S., and B. S. BUTLER, The Yakutat Bay region, Alaska, Prof. Pap., U. S. Geol. Surv. $64,1909$.

Division of the Geological Sciences, California Institute of Technology, Pasadena, California

(Communicated manuscript received December 29, 1952; open for formal discussion until March 1, 1954.) 